\title{
A new scenario framework for climate change research: background, process, and future directions
}

\author{
Kristie L. Ebi • Stephane Hallegatte • Tom Kram • \\ Nigel W. Arnell • Timothy R. Carter • Jae Edmonds • \\ Elmar Kriegler • Ritu Mathur • Brian C. O’Neill • \\ Keywan Riahi • Harald Winkler • \\ Detlef P. Van Vuuren • Timm Zwickel
}

Received: 30 January 2013 / Accepted: 28 August 2013 /Published online: 27 September 2013

(C) Springer Science+Business Media Dordrecht 2013

\begin{abstract}
The scientific community is developing new global, regional, and sectoral scenarios to facilitate interdisciplinary research and assessment to explore the range of possible future climates and related physical changes that could pose risks to human and natural systems; how these changes could interact with social, economic, and environmental development pathways; the degree to which mitigation and adaptation policies can avoid and reduce risks; the costs and benefits of various policy mixes; and the relationship of future climate change adaptation and mitigation policy responses with sustainable development. This paper provides the background to and process of developing the conceptual framework for these scenarios, as described in the three subsequent papers in this Special Issue (Van Vuuren et al., 2013; O’Neill et al., 2013; Kriegler et al., Submitted for publication in
\end{abstract}

This article is part of the Special Issue on "A Framework for the Development of New Socio-economic Scenarios for Climate Change Research" edited by Nebojsa Nakicenovic, Robert Lempert, and Anthony Janetos.

K. L. Ebi $(\bowtie)$

ClimAdapt, LLC, 424 Tyndall Street, Los Altos, CA, USA

e-mail: krisebi@essllc.org

S. Hallegatte

The World Bank, Washington, DC, USA

T. Kram • D. P. Van Vuuren

Netherlands Environmental Assessment Agency (PBL), Bilthoven, The Netherlands

N. W. Arnell

Walker Institute for Climate System Research, Reading, UK

T. R. Carter

Finnish Environment Institute (SYKE), Climate Change Programme, Helsinki, Finland

J. Edmonds

Joint Global Change Research Institute, Baltimore, USA

E. Kriegler • T. Zwickel

Potsdam Institute for Climate Impact Research, Potsdam, Germany 
this special issue). The paper also discusses research needs to further develop, apply, and revise this framework in an iterative and open-ended process. A key goal of the framework design and its future development is to facilitate the collaboration of climate change researchers from a broad range of perspectives and disciplines to develop policy- and decision-relevant scenarios and explore the challenges and opportunities human and natural systems could face with additional climate change.

\section{Introduction}

The scientific community is in the midst of developing a new set of scenarios to underpin climate change research and permit the integrated analysis of future climate impacts, vulnerabilities, adaptation, and mitigation. These alternative pathways of plausible future development require the assessment of atmospheric composition; the magnitude and extent of future climate change; associated potential impacts on physical, natural, and human systems; the costs and possible effectiveness of mitigation and adaptation policies; the interactions among and trade-offs between climate change impacts and policies of adaptation and mitigation; and the relationship between climate change and socioeconomic development (Moss et al. 2008, 2010). These scenarios are being designed to represent a wide range of uncertainty in mitigation efforts required to achieve particular radiative forcing pathways, and in adaptation efforts that could be undertaken to prepare for and respond to the climatic changes and impacts associated with those pathways.

We summarize the rationale for and process of developing a conceptual framework for the new scenarios. We also discuss a number of important research directions required to further develop and apply the conceptual framework. The conceptual framework is described in the subsequent three papers in this Special Issue (van Vuuren et al. 2013; O'Neill et al. 2013; Kriegler et al. Submitted for publication in this special issue).

The new scenario process builds on previous processes of global scenario development, particularly those directed specifically at climate change, including the IS92 scenarios (Leggett et al. 1992) and the scenarios developed in the 1990s for the Intergovernmental Panel on Climate Change (IPCC) Special Report on Emission Scenarios (SRES) (Nakicenovic et al. 2000). The SRES scenarios were developed to represent the range of driving forces and emissions in the scenario literature, including reflecting understanding about underlying uncertainties. They were developed by first creating internally consistent storylines of possible future worlds (Nakicenovic et al. 2000). The four main storylines (labeled using neutral identifiers A1, A2, B1 and B2) describe the relationships between driving forces of emissions of greenhouse gases and other radiatively active substances and their evolution over time. Each storyline represents different demographic, social, economic, technological, and environmental

R. Mathur

TERI, New Delhi, India

B. C. O’Neill

National Center for Atmospheric Research (NCAR), Boulder, USA

K. Riahi

International Institute for Applied System Analysis, Laxenburg, Austria

H. Winkler

University of Cape Town, Cape Town, South Africa

D. P. Van Vuuren

Utrecht University, Utrecht, The Netherlands 
development pathways, intentionally designed to produce a wide range of future emissions pathways. For each storyline, several scenarios were developed using different integrated models of the global energy-economy-environment system to examine the range of possible outcomes associated with similar assumptions about driving forces. Altogether, 40 scenarios were quantified for the SRES report, six of which were selected as illustrative scenarios (one for each of the storylines, plus additional high and low emissions variants of the A1 storyline). By design, the SRES scenarios assumed no specifically targeted climate mitigation or adaptation policies and measures. Quantification of the storylines resulted in estimated emissions of greenhouse gases and sulfur that were used as input into climate models to project changes in patterns of climate variables such as temperature and precipitation. These projections have been extensively used to estimate possible impacts associated with each scenario.

Progress since the SRES in demographic and socioeconomic projections, and in impact, adaptation, and mitigation analyses, has fueled demand for this knowledge to be incorporated into new scenarios. The SRES scenarios are becoming dated in terms of scientific understanding and in their demographic and socioeconomic assumptions. New scenarios are needed to address more effectively questions concerning the policies and practice of preparing for and responding to climate change. Such scenarios also need to cover a wider range of greenhouse gas concentrations (including those that can be reached by implementing mitigation measures) and to facilitate improved integration of mitigation, adaptation, and impact analyses.

The new scenario process is not being organized or led by the IPCC, nor by any other international institution. Some reasons for this include the greater scientific credibility of scenarios developed by the research community, the potentially open-ended involvement of research groups across a wide range of disciplines and geographic regions, and greater control over a scenario building process free from institutional timetables. Moreover, it was felt that the community was mature enough to self-organize. None of these considerations exclude the IPCC or another institution from facilitating the process.

The process was designed based on extensive discussions in multiple fora, and was initiated in a 2006 workshop whose participants primarily included members of the climate and integrated assessment modeling communities (Meehl and Hibbard 2007). Discourse at subsequent workshops resulted in the preparation of a roadmap to develop new scenarios that was formalized at the Expert Meeting on Scenarios organized by the IPCC at Noordwijkerhout, Netherlands, in 2007 (Moss et al. 2008). This roadmap details a threestep, so-called parallel process (Moss et al. 2010) consisting of a preparatory phase (serving the needs of the climate modeling community), a parallel phase (climate modeling and socioeconomic scenario development), and an integration phase (development of scenarios addressing mitigation, adaptation and impacts). This process was designed to be responsive to the needs of national and international assessments; to develop a set of reference stabilization pathways as the first building block for the new community scenarios; and to address the climate modeling community interest in investigating a wider range of forcing outcomes and in having greenhouse gas emissions and concentrations prescribed to investigate climate-carbon cycle feedbacks.

The new scenario process follows a different logic than was used in the SRES. SRES scenarios were developed using a forward-looking logic that started by first describing driving forces, and then modeling the resulting emissions and atmospheric concentrations of greenhouse gases and aerosols. Climate models were then used to project the magnitude and pattern of climate change under different scenarios. In contrast, in the new scenario process, the community first agreed to establish a small number of pathways of atmospheric concentrations (and their associated radiative forcing) over the 21 st century, and then to 
simultaneously develop climate change projections and socioeconomic pathways consistent with the concentration pathways (Meehl and Hibbard 2007; Hibbard et al. 2007). Based on this design, activities have been scheduled (and performed) as part of the three phases indicated above:

- In phase 1 , the integrated assessment modeling community developed four representative concentration pathways (RCPs) and the emissions that would produce them, taking into consideration the full basket of greenhouse gases, land use change, and other factors, and corresponding to the four chosen concentration levels. The development of the four RCPs is documented in a special issue of Climatic Change (Van Vuuren et al. 2011).

- In the current phase (phase 2), the RCPs have been used as the basis for simulations with earth system models as part of the Climate Model Intercomparison Project (CMIP-5), producing projections of the magnitude and pattern of climate change over this century and, in some cases, to 2300 (Taylor et al. 2012). At the same time, the integrated assessment modeling (IAM) and impacts, adaptation, and vulnerability (IAV) ${ }^{1}$ communities are developing new descriptions of future socioeconomic conditions, the Shared Socioeconomic Pathways (SSPs). O’Neill et al. (2013) describes the conceptual framework underlying the SSPs.

- In phase 3, scenarios for use by the climate change science community will be created, integrating the descriptions of socioeconomic development with the climate change projections and with assumptions about climate mitigation and adaptation policies. The conceptual framework for this integration is discussed in van Vuuren et al. (2013).

An early question faced in this process was whether the approach of beginning with a set of pre-defined forcing pathways - the RCPs — and their climate change outcomes would constrain the range of future socioeconomic conditions that could be considered. An insight gained from the SRES (Nakicenovic et al. 2000) and confirmed by Van Vuuren et al. (2012) is that the magnitude and extent of greenhouse gas emissions does not have a one-to-one relationship with demographic and socioeconomic development. That is, multiple "reference" (i.e. no climate policy) socioeconomic pathways could lead to the same RCP, e.g. a development pathway with a large population and low emissions per capita can lead to the same emission or radiative forcing pathway as a development pathway with a smaller population but higher emissions per capita. Similarly, a particular socioeconomic pathway could be consistent with a wide range of emission or radiative forcing pathways, depending on the stringency and extent of mitigation efforts.

Therefore, a range of demographic and socioeconomic development pathways can be considered when creating scenarios in phase three of the parallel process by combining future socioeconomic conditions, as described in the SSPs, with possible mitigation and adaptation policies to reach radiative forcing pathways over the 21 st century as defined by the range of the RCPs. The conceptual framework described in van Vuuren et al. (2013), O’Neill et al. (2013) and Kriegler et al. (Submitted for publication in this special issue) provides a flexible toolkit from which researchers can create scenarios to address specific research and policy-relevant questions.

\section{Process of developing the new socioeconomic scenarios}

Over the past 2 to 3 years, researchers from the IAM and IAV communities turned to the task of developing socioeconomic development pathways, with a series of meetings held to facilitate progress and synthesize approaches. A joint IPCC-NRC (U.S. National Research Council)

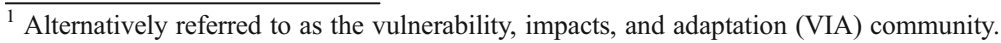


workshop in Washington, DC, in February 2010, explored the needs for socioeconomic and environmental futures that could be used with climate scenarios (NRC 2010) and served as a stimulus for initial proposals for frameworks within which such scenarios could be developed (Van Vuuren et al. 2012; Kriegler et al. 2012). An IPCC Workshop on Socioeconomic Scenarios held in Berlin in November 2010 brought together researchers from the IAM, IAV, and climate modeling communities to consider the task. The workshop led to the adoption of some main elements of a unified framework for developing a small set of Shared Socioeconomic Pathways (SSPs) and their use in conjunction with the RCPs, policy assumptions, and associated climate model simulations to create scenarios to facilitate integrated research and assessment (IPCC 2012).

Subsequent to the Berlin meeting, a team of authors produced a draft discussion paper presenting an over-arching conceptual framework for the development and use of SSPs. This draft was posted on a public website (www.isp.ucar.edu/socio-economic-pathways) and was subject to widespread community review. Invitations to review the draft were sent to personal contacts as well as to key community email lists, such as: the IPCC Fifth Assessment Report (AR5) Working Group II and Working Group III authors; listservs for HDGEC (Human Dimensions of Global Environmental Change; http://istserver.ciesin.columbia.edu/cgi-bin/wa? $\mathrm{A} 0=\mathrm{HDGEC}$ ) and CLIMLIST (http://climlist.wku.edu/); and the Population-Environment Research Network. In addition, as discussed in Wilbanks and Ebi (2013), review comments were solicited from experts in developing countries.

In early November 2011, a meeting in Boulder, Colorado, was held to adopt a basic set of narratives for the SSPs and to outline priorities for further activities (O'Neill et al. 2012). The draft discussion paper served as the key background document. Many of the presentations were directly relevant to the SSP framework and its implementation, and are reflected in other papers in this Special Issue. Most recently, a workshop co-sponsored by the IPCC and the government of the Netherlands in the Hague in May 2012 afforded an opportunity to broaden the dialogue on the draft SSP narratives, incorporating perspectives from diverse areas of expertise and geographic regions, and to present initial quantifications of the SSPs. Participants included IAV, IAM, and international futures researchers and practitioners from developed and developing countries.

Throughout the process, there have been active efforts to engage experts from IAM and IAV communities in both developed and developing countries. IPCC sponsorship of the Berlin (2010) and Netherlands (2012) meetings facilitated the participation of developing country experts in formative discussions. This participatory process for developing the framework for new scenario development, including community review, resulted in a number of important extensions and improvements of the initial proposed framework. The revised and extended SSP framework is summarized in Van Vuuren et al. (2013), O’Neill et al. (2013) and Kriegler et al. (Submitted for publication in this special issue) in this Special Issue.

Similar to the framework, the draft SSP narratives and initial quantifications of the SSP socioeconomic and demographic projections were posted on public websites and subject to community review during 2012. The preliminary narratives and SSP quantifications projections can be accessed at the narratives webpage at https://www.isp.ucar.edu/narratives-sspsworking-group and the SSP database at https://secure.iiasa.ac.at/web-apps/ene/SspDb. The quantification of the main SSP elements, associated narratives, and initial IAM scenarios are under development as of this writing.

\section{New scenario process framework papers}

Van Vuuren et al. (2013), O’Neill et al. (2013) and Kriegler et al. (Submitted for publication in this special issue) describe the conceptual framework for developing new scenarios based on 
combining socioeconomic development pathways, climate change futures, and policy responses. The new scenarios are being developed using a scenario matrix approach (Van Vuuren et al. 2013) that provides the landscape within which a particular scenario can be located based on the state of human societies and ecological systems as described in the SSPs (O'Neill et al. 2013); the degree of anthropogenic interference with the climate system (measured in terms of radiative forcing as described, for example, in the RCPs); and shared assumptions on mitigation and adaptation policies (Kriegler et al. Submitted for publication in this special issue). The SSPs define the state of human societies and ecological systems at a macro scale and have two elements: a narrative storyline and a set of quantified measures that define the state of society as it evolves over the 21 st century, including existing climate policies but without new (future) climate policies, and under the assumption of no significant climate feedback on the development pathway. The SSPs are distinguished on the basis of challenges to adaptation and mitigation, rather than on emissions pathways as was done for the SRES. Each combination of an SSP and a radiative forcing level defines a family of macro-scale scenarios. However, the RCP level indicates only the target radiative forcing for mitigation policy. Scenarios designed to achieve a RCP level of radiative forcing must specify particular mitigation and adaptation policies adopted to reduce emissions and cope with resulting climate change. Because there are a wide variety of such policies that could achieve mitigation or adaptation goals, Shared climate Policy Assumptions (SPAs) provide a means to employ common assumptions across a wide variety of studies in investigate the consequences of particular policy approaches. SPAs capture key climate policy dimensions not specified in the SSPs, describing features such as global and sectoral coverage of greenhouse gas reduction regimes and/or adaptation effectiveness in different world regions (Kriegler et al. Submitted for publication in this special issue). Note that because GDP and other elements within a SSP could be affected by climate policies and by climate change impacts, developing scenarios that include these factors may well modify some of the reference SSP assumptions (see Van Vuuren et al. 2013; Kriegler et al. Submitted for publication in this special issue). SPAs can have a significant impact on an integrated scenario.

\section{Future research directions}

The development of new scenarios is a long-term and iterative process, with further research needed, including the creation of extended sectoral and regional versions of the SSPs for use in impact, adaptation, and mitigation studies; and the development and application of SPAs in the scenario framework (Kriegler et al. 2012). The conceptual framework, and possibly the actual content of the SSPs and SPAs, is expected to evolve with use, as knowledge and understanding accumulate.

Activities needed to test, analyze, and revise the framework include evaluating the usefulness of the new scenarios in impacts, adaptation, mitigation, and climate policy analyses, and in informing decision-making. The framework and resulting scenarios will not be able to satisfy all needs or answer all research questions. Therefore, it is critical to distinguish (1) policyrelevant and decision-making questions the framework can help answer; (2) questions the framework is ill equipped to answer, and, most importantly, (3) questions the framework can help answer with some minor adjustments. This implies that the types of questions posed in testing the scenarios should be designed to determine the framework's limits of usefulness and how those could be overcome.

Research and implementation is increasingly considering climate policy as one aspect of development policies, calling for an integrated design of climate, development, and other environmental and social policies. Integrated approaches will test the framework by integrating the drivers of development contained in the SSP narratives, the climate policies contained in 
SPAs, and the magnitude and extent of climate change. Because sustainable development is a policy goal, a further advance could be to explicitly model developmental pathways as an outcome.

Additional tasks for testing and analysis include:

- Re-interpreting the scenario framework in relation to other scenarios in the existing literature. Explicit links can be made between the new and previous scenarios, for instance through the development of methods to connect (and maybe scale) assumptions and results (e.g. Table 4 in Van Vuuren et al. 2012; Van Vuuren and Carter Submitted for publication in this special issue). This could include the translation of the new "outcome-based" organization (with scenario characteristics referenced against their resulting challenges to mitigation and adaptation) into the more traditional "input-based" organization, where scenarios are represented according to their drivers (e.g. population, technology).

- Determining the relevance of the SSP narratives (and the axes of challenges to mitigation and challenges to adaptation) for different problems, scales, and research questions. There is a need to test various indicators to measure challenges to adaptation and mitigation, but also to test alternative dimensions for locating SSPs. Additional dimensions may be useful for organizing SSPs (e.g. aggregate material consumption and equity in consumption), and to investigate issues other than climate change (e.g. longterm health issues).

- Regional, sectoral, and climatological analyses, which raise questions of scenario scaling. For instance, analysts might consider applying pattern-scaling techniques to represent regional climates consistent with future concentration pathways that lie between RCPbased climate outcomes (e.g. Ishizaki et al. 2012). Downscaling methods also may be employed to create regional and sectoral scenarios that are consistent with global scenarios. The global scenario provides boundary conditions and constraints on local and sectoral scenarios, but cannot be downscaled in a deterministic way as with the climate system. Global scenarios constrain local ones: for example, a country is unlikely to have large local use of electric vehicles if they are not available elsewhere in the world, although the possibility cannot be ruled out entirely. But the constraints placed by global boundary conditions on local scenarios are not deterministic: a country can experience an increase in inequality in a world where inequality is generally decreasing. Many different approaches have been proposed to downscale scenarios, but there is no scientific consensus on preferred approaches (e.g. van Vuuren et al. 2010). Although some global variables are clearly relevant to local scenarios (e.g. with global markets, the oil price is similar in all countries), local and global evolutions can diverge in other dimensions (e.g. local governance can worsen in a world with improved governance).

- Local and sectoral scale scenario development will benefit future global scenarios, such as by identifying "impossible" evolutions where scenarios appear plausible at global but not local (or sectoral) scales.

- Consideration of "surprise" scenarios. To answer some of the criticisms raised about past scenario exercises, participants at the Boulder meeting noted the desirability of introducing tipping points and "wild cards" in an analysis, to test policies against a broader set of scenarios and some unlikely but not impossible surprises (e.g. more rapid than expected technological changes or radical change in political landscapes).

A conclusion from the 2011 Boulder meeting was the need for a larger set of scenarios to meet the range of research needs and the potential demands from operational decision-makers facing long-term choices (e.g. concerning infrastructure or urban development). The "best" scenarios to analyze a water management decision or an energy tax decision are unlikely to be 
the same. The selection of the most relevant scenarios to inform a given decision - a process sometimes referred to as scenario elicitation — is at the heart of some decision-making methods (see Rozenberg et al. 2013).

We suggest building on existing scenario databases ((e.g. the Energy Modeling Forum (http://emf.stanford.edu/) or the Integrated Assessment Modeling Consortium database for the IPCC 5th Assessment Report (https://secure.iiasa.ac.at/web-apps/ene/AR5DB/)) to create a sustainable multi-model database that will both contribute to the scenarios and facilitate the development of the next generation of scenarios. The database can be used to provide scenarios for a specific research question or operational use, as well as to provide a set from which to select the next generation of scenarios (see methodological options in Schweizer and O'Neill 2013; Rozenberg et al. 2013). In particular, it would make it possible for various modeling groups to produce and share their scenarios ("let a thousand flowers bloom"). Development of a database also will facilitate discussions of how scenarios can be chosen in view of particular policy decisions. One such database has been established and hosts the draft quantitative socioeconomic and demographic projections of the SSPs (https://secure.iiasa.ac.at/web-apps/ene/SspDb/). Plans are to extend the database in due course to host the IAM SSP scenario results.

\section{Conclusions}

The conceptual framework for new scenario development, as described in Van Vuuren et al. (2013), O’Neill et al. (2013) and Kriegler et al. (Submitted for publication in this special issue), offers an approach to develop qualitative and quantitative scenarios for climate change research and assessment using a range of development pathways. The scenarios created from the combination of the SSPs, RCPs, and SPAs can help answer questions about the possible magnitude of impacts of climate change, the extent to which adaptation and mitigation policies can reduce those risks, the human and financial resources required to implement climate and sustainable development policies, and the range of uncertainty in all these estimates. It is hoped that a wide range of interdisciplinary climate change researchers will work together to build policy- and decision-relevant scenarios and explore what those scenarios imply for the challenges and opportunities human and natural systems could face with increasing climate change.

The scenario development process being followed is more complex than the process followed for the SRES. By unpacking scenario elements into emission pathways, socioeconomic development pathways, and policy options, the process is creating a flexible toolkit from which researchers can construct scenarios relevant for a much broader range of questions than could be addressed by earlier scenarios. As described in Van Vuuren et al. (2013), it will now to be possible to explore the possible consequences of different development pathways in a world on a particular emission pathway, or the possible consequences of different emission pathways in a world on a particular development pathway. For example, if the world is making progress towards sustainable development, then what might be the burden of malnutrition attributable to climate change under different RCPs? Or, if the world is on track for $4.5 \mathrm{~W} / \mathrm{m}^{2}$ in 2100 , then what might be the burden of malnutrition attributable to climate change under different development pathways?

Such a flexible process creates additional tasks for the scientific community. To facilitate comparison of scenarios, it will be necessary for the community to agree on which of the large number of scenarios that could be created using the conceptual framework should be considered "marker scenarios" that all analysts would be recommended to adopt. There also 
will need to be additional efforts in communication and outreach, to facilitate understanding and use of this approach by researchers and policymakers.

In addition, the scientific community needs to decide on the timing for further scenario development. The scenario process was originally designed with long-term needs for facilitating research and development in mind, although it was hoped that some early analysis based on new scenarios could be available for assessment in the IPCC AR5. It transpired there was sufficient time ahead of AR5 publication deadlines for only a few SSPand RCP-based integrated scenarios to be applied in studies and reported in the literature. For example, two modeling intercomparison projects used a preliminary version of the SSPs, along with RCP-based climate simulations, in their experiments (the Agricultural Model Intercomparison and Improvement Project (AgMIP); http://www.agmip.org/; and the Inter-Sectoral Impact Model Intercomparison Project (ISI-MIP); http://www.pik-potsdam.de/research/climate-impacts-and-vulnerabilities/research/rd2-cross-cutting-activities/isi-mip).

To manage timelines going forward, options include to:

- Not establish a fixed timeline, taking a more flexible and endogenous approach (some would say an adaptive management approach) in which new SSPs and quantified scenarios are produced when problems (and solutions) are identified.

- Establish a timeline taking into consideration the likely needs of future international scientific assessments such as a possible IPCC Sixth Assessment Report.

Now is an appropriate time to begin a longer-term iterative process for scenario development, creating a database of impact, adaptation, and mitigation studies that apply global, regional, and sectoral scenarios for use in decision-making and assessments, and deciding as a community on next steps in creating scenarios relevant for the widest possible climate change research community.

\section{References}

Intergovernmental Panel on Climate Change (IPCC) (2012) Workshop Report of the Intergovernmental Panel on Climate Change Workshop on Socioeconomic Scenarios [Edenhofer O, Pichs-Madruga R, Sokona Y, Barros V, Field CB, Zwickel T, Schloemer S, Ebi K, Mastrandrea M, Mach K, von Stechow C (eds)]. IPCC Working Group III Technical Support Unit, Potsdam Institute for Climate Impact Research, Potsdam Germany, pp 51

Hibbard K, Meehl GA, Cox PM, Friedlingstein P (2007) A strategy for climate change stabilization experiments. EOS 88(20), pages 217, 219, 221

Ishizaki Y, Shiogama H, Emori S, Yokohata T, Nozawa T, Ogura T, Abe M, Yoshimori M, Takahashi K (2012) Temperature scaling pattern dependence on representative concentration pathway emission scenarios. A letter. Clim Chang 112:535-546

Kriegler E, O’Neill BC, Hallegatte S, Kram T, Lempert R, Moss R, Wilbanks T (2012) The need for and use of socioeconomic scenarios for climate change analysis: a new approach based on shared socioeconomic pathways. Glob Environ Chang 22(4):807-822

Kriegler E, Edmonds J, Hallegatte S, Ebi KL, Kram T, Riahl K, Winkler H, van Vuuren DP (submitted for this issue) A new scenario framework for climate change research: the concept of shared climate policy assumptions. Climatic Change

Leggett J, Pepper W, Swart RJ (1992) Emissions scenarios for the IPCC: an update. In: Houghton JT, Callander BA, Varney SK (eds) Climate change 1992. The supplementary report to the IPCC scientific assessment. Cambridge University Press, Cambridge, pp 71-95

Meehl GA, Hibbard K (2007) Aspen Global Change Institute (AGCI). 2007. Summary Report: A strategy for climate change stabilization experiments with AOGCMs and ESMs. Aspen Global Change Institute 2006 Session: Earth System Models: The Next Generation. Report from Aspen Global Change Institute session, July 30-August 5, 2006 and joint WGCM/AIMES Steering Committee Meeting 27 September, 2006 (Aspen, Colorado, July 30-August 5, 2006). http://www.agci.org/dB/PDFs/Publications/06S1_ WhitePaper.pdf 
Moss RH, Babiker M, Brinkman S, Calvo E, Carter T, Edmonds J, Elgizouli I, Emori S, Erda L, Hibbard K, Jones R, Kainuma M, Kelleher J, Lamarque JF, Manning M, Matthews B, Meehl J, Meyer L, Mitchell J, Nakićenović N, O’Neill B, Pichs R, Riahi K, Rose S, Runci P, Stouffer R, van Vuuren D, Weyant J, Wilbanks T, van Ypersele JP, Zurek M (2008) Towards new scenarios for analysis of emissions, climate change, impacts, and response strategies. Intergovernmental Panel on Climate Change, Geneva

Moss RH, Edmonds JA, Hibbard KA, Manning MR, Rose SK, van Vuuren DP, Timothy R, Carter TR, Emori S, Kainuma M, Kram T, Meehl GA, Mitchell JFB, Nakicenovic N, Riahi K, Smith SJ, Stouffer RJ, Thomson AM, Weyant JP, Wilbanks TW (2010) The next generation of scenarios for climate change research and assessment. Nature 463:747-756

Nakicenovic N, Alcamo J, de Vries B et al (2000) Special report on emissions scenarios: a special report of working group III of the Intergovernmental Panel on Climate Change. Cambridge University Press, Cambridge

O’Neill BC, Kriegler E, Riahl K, Ebi KL, Hallegatte S, Carter TR, Mathur R, van Vuuren D (2013) A new scenario framework for climate change research: the concept of shared socio-economic pathways. Clim Chang. doi:10.1007/s10584-013-0905-2

O’Neill BC, Carter TR, Ebi KL, Edmonds J, Hallegatte S, Kemp-Benedict E, Kriegler E, Mearns L, Moss R, Riahi K, van Ruijven B, van Vuuren D (2012) Meeting Report of the Workshop on The Nature and Use of New Socioeconomic Pathways for Climate Change Research, Boulder, CO, November 2-4, 2011. Available at: http://www.isp.ucar.edu/socio-economic-pathways

National Research Council (2010) Panel on Socioeconomic Scenarios for Climate Change Research and Assessment, Describing Socioeconomic Futures for Climate Change Research and Assessment: Report of a Workshop

Rozenberg J, Guivarch C, Lempert R, Hallegatte S (2013) Building SSPs for climate policy analysis: a scenario elicitation methodology to map the space of possible future challenges mitigation and adaption. Clim Chang. doi:10.1007/s10584-013-0904-3

Schweizer,V., O’Neill, B. (2013). Systematic construction of global socioeconomic pathways using internally consistent element combinations. Clim Chang. doi:10.1007/s10584-013-0908-z

Taylor KE, Stouffer RJ, Meehl GA (2012) An overview of CMIP5 and the experiment design. Bull Am Meteorol Soc 93:485-498. doi:10.1175/BAMS-D-11-00094.1

van Vuuren DP, Carter TR (submitted for this issue) Climate and socio-economic scenarios for climate change research and assessment: reconciling the new with the old. Climatic Change

van Vuuren DP, Edmonds JA, Kainuma M, Riahi K, Weyant J (2011) A special issue on the RCPs. Clim Chang 109:1-4. doi:10.1007/s10584-011-0157-y

van Vuuren DP, Riahi K, Moss R, Edmonds J, Thomson A, Nakicenovic N, Kram T, Berkhout F, Swart R, Janetos A, Rose SK, Arnell N (2012) A proposal for a new scenario framework to support research and assessment in different climate research communities. Glob Environ Chang 22:21-35

van Vuuren DP, Kriegler E, O’Neill BC, Ebi KL, Riahi R, Carter TR, Edmonds J, Hallegatte S, Kram T, Mathur R, Winkler H (2013) A new scenario framework for climate change research: scenario matrix architecture. Clim Chang. doi:10.1007/s10584-013-0906-1

van Vuuren DP, Smith SJ, Riahi K (2010) Downscaling socioeconomic and emissions scenarios for global environmental change research: a review. WIREs Clim Chang 1:393-404

Wilbanks TJ, Ebi KL (2013) SSPs from an impact and adaptation perspective. Clim Chang. doi:10.1007/ s10584-013-0903-4 